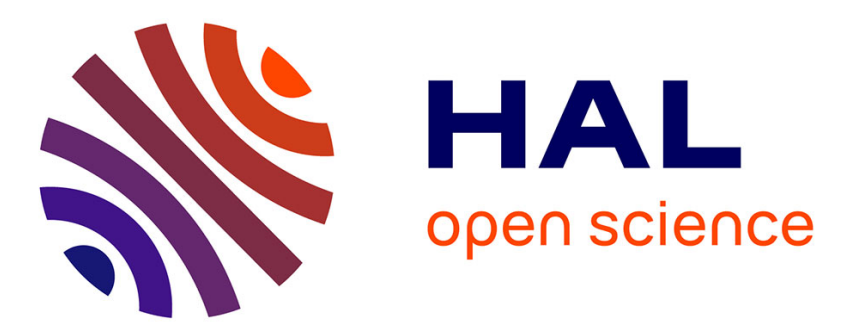

\title{
Experimental Validation of Numerical Simulations of a New-Generation NiTi Endodontic File Under Bending
}

Valérie Chevalier, Laurent Pino, Reza Arbab Chirani, Sylvain Calloch, Shabnam Arbab-Chirani

\section{- To cite this version:}

Valérie Chevalier, Laurent Pino, Reza Arbab Chirani, Sylvain Calloch, Shabnam Arbab-Chirani. Experimental Validation of Numerical Simulations of a New-Generation NiTi Endodontic File Under Bending. Journal of Materials Engineering and Performance, 2018, 10.1007/s11665-018-3674-2 . hal01890035

\section{HAL Id: hal-01890035 \\ https://hal-ensta-bretagne.archives-ouvertes.fr/hal-01890035}

Submitted on 5 Mar 2019

HAL is a multi-disciplinary open access archive for the deposit and dissemination of scientific research documents, whether they are published or not. The documents may come from teaching and research institutions in France or abroad, or from public or private research centers.
L'archive ouverte pluridisciplinaire HAL, est destinée au dépôt et à la diffusion de documents scientifiques de niveau recherche, publiés ou non, émanant des établissements d'enseignement et de recherche français ou étrangers, des laboratoires publics ou privés. 


\title{
Experimental Validation of Numerical Simulations of a New-Generation NiTi Endodontic File Under Bending
}

\author{
Valérie Chevalier, Laurent Pino, Reza Arbab Chirani, Sylvain Calloch, and Shabnam Arbab Chirani
}

The superelasticity of NiTi shape memory alloy has been used in endodontics since the 1990s. To study the mechanical behavior of endodontic instruments, a traditional approach consists in experimental investi-gations. However, finite element analysis constitutes another way to assess their mechanical behavior and to facilitate their design. The main aim of this study is to compare experimental and numerical bending results on different structures ( $\mathrm{NiTi}$ wire, spreader, and instruments) to estimate the reliability of the finite element simulations. These investigations were carried out as follows. Firstly, experimental material parameters identification was performed using NiTi wires. These parameters were implemented in an appropriate NiTi model. Bending was numerically applied to the meshed structures generated by the finite element method. Experimental tests were performed on real structures under bending, with exactly the same loading, in order to compare experimental and numerical results. These results were in good agreement for each of the considered structures. This enabled the validation of the simulation results and the use of simulations to design new endodontic instruments.

\begin{abstract}
Keywords bending, biomedical, model validation, modeling and simulation, NiTi endodontic instruments, nondestructive testing
\end{abstract}

\section{Introduction}

Nickel-Titanium (NiTi) rotary instruments have been used since the 1990s. They are now employed by the vast majority of dentists. This is due to the behavior of NiTi alloy. This shape memory alloy (SMA) exhibits superelasticity, which ordinary alloys do not have. This property means that the material can reach a total strain of $6-8 \%$, without developing residual strain. This behavior relies on the phase transformation of austenite to martensite under stress, when the temperature is higher than a characteristic temperature of the material called Ms. This phase transformation is completely reversible during unloading (Ref 1). The superelasticity makes the endodontic instruments more flexible, which has improved the quality of root canal chemomechanical preparation and decreased root canal transportation, in comparison with stainless steel endodontic files (Ref 2). Moreover, these NiTi instruments are engine driven, which enables a faster and more effective preparation (Ref 3).

Valérie Chevalier, Department of Endodontics and Conservative Dentistry, Dental School-Hospital University CHRU, University of Bretagne Occidentale, UBO, Brest, France; and Univ. Bretagne Occidentale, UMR CNRS 6027, IRDL, 29200 Brest, France; Laurent Pino and Shabnam Arbab Chirani, ENI Brest, UMR CNRS 6027, IRDL, 29200 Brest, France; Reza Arbab Chirani, Department of Endodontics and Conservative Dentistry, Dental School-Hospital University CHRU, University of Bretagne Occidentale, UBO, Brest, France; and Laboratory of Medical Information Processing, LaTIM-INSERM UMR 1101, Brest, France; and Sylvain Calloch, ENSTA Bretagne, UMR CNRS 6027, IRDL, 29200 Brest, France. Contact e-mail: arbab@enib.fr.
To perform root canal preparation, several consecutive endodontic instruments are traditionally used. During this preparation, the mechanical loadings applied to the endodontic instruments are multiaxial (torsion and bending) and nonproportional (i.e., out of phase). They can sometimes lead to intracanal file fracture. This instrument fracture is due to torsional stress or cyclic fatigue under bending (Ref 4). To reduce intracanal fracture and to improve root canal shaping, the geometries of the instruments and the NiTi alloys were improved (Ref 5). With the same aims, recently a new concept of preparation with a single disposable instrument with reciprocal working motion has been proposed (Ref 6,7). This concept results in extended fatigue life (Ref 8,9).

Another evolution consists in a single disposable instrument, but used in a continuous rotation movement. This concept was originally proposed with the OneShape ${ }^{\circledR}$ instrument (MicroMega, Besançon, France), made of a conventional austenitic NiTi alloy at room temperature. This instrument aims to simplify the procedure while keeping the traditional continuous rotation motor. The single use is intended to reduce the risk of instrument fracture and to enhance biological safety. The OneShape ${ }^{\circledR}$ single instrument is available only in one instrument, which has a tip size of $25(250 \mu \mathrm{m})$ and a constant taper of .06 , with a variable pitch. It consists of three asymmetric cross sections in order to shape each portion of the root canal: a triple helix section at the tip, transforming into a two-cuttingedge section in the middle, and then ends in an S-section at the shank (Ref 10-12). Most of the studies of the OneShape ${ }^{\circledR}$ instrument concern its cyclic fatigue behavior (Ref 13, 14). However, the mechanical behavior of the OneShape ${ }^{\circledR}$ instrument under bending is poorly documented. To our knowledge, only Elnaghy and Elsaka (Ref 11) and Wang et al. (Ref 15) performed such bending tests.

Endodontic file behavior has traditionally been explored through experimental studies. However, numerical analysis constitutes another option to study the mechanical behavior of files. It takes into account geometry characteristics, material 
parameters, and boundary conditions and aims to replicate reality as closely as possible (Ref 16).

Since the beginning of this century, in endodontics these numerical approaches have developed at the same time as in other fields such as the car industry, aeronautics, and especially medicine. For example, the behavior of NiTi was studied by finite element analysis for a self-expanding vascular stent (Ref 17, 18) and orthopedic staples (Ref 19).

In endodontics, most of the numerical investigations on NiTi file behavior consist in comparisons of the mechanical behavior of instruments under bending or torsion, while varying either the geometrical parameters (Ref 20-28) or the NiTi alloy employed (Ref 16, 29-32). To approximate the real conditions of use, the insertion of a file in a geometrical root canal was simulated and the behavior of the instrument was studied (Ref 33-38).

The numerical method could constitute a reliable tool to improve current and future endodontic instruments. The numerical simulations enable the geometrical characteristics or the material parameters (after thermal treatment for example) to evolve and to assess the impact of these changes on the mechanical behavior of the instrument, before prototyping.

However, the numerical simulation of the mechanical behavior of endodontic files remains a challenge for several reasons: The file geometries and the mechanical loadings are complex. Moreover, the mechanical behavior of a NiTi alloy is strongly nonlinear and highly affected by the multiaxial and non-proportional aspects of the loading. That is why the numerical data must be compared with experimental tests in order to allow the validation of the numerical models and their use in safe conditions (Ref 16, 39).

The main aim of the present study is to compare experimental and numerical results under bending on different structures (NiTi wire, Spreader, Hero ${ }^{\circledR}$, and OneShape ${ }^{\circledR}$ endodontic instruments) and to assess the reliability of the numerical simulations under Saint-Sulpice's SMA model (Ref 40). The second objective is to study the mechanical behavior under bending of the new-generation OneShape ${ }^{\circledR}$ monoinstrument and to assess differences in bending performance between this new instrument and a traditional endodontic instrument of the same manufacturer with comparable geometrical characteristics $\left(\right.$ Hero $^{\circledR}(250 \mu \mathrm{m}$ tip diameter/.06 taper)).

\section{Materials and Methods}

\subsection{Experimental Tests}

To study the mechanical behavior of OneShape ${ }^{\circledR}$ under bending, an experimental setup with control of the boundary conditions was designed. To check this setup, samples of growing complexity (wires, spreaders, instruments) were tested under the same boundary conditions. This setup was chosen in order to ease the comparison of experimental results with numerical ones. Numerical simulations were then performed on the same structures as those used during experimental tests and with the same boundary conditions.

2.1.1 Samples. First, the experimental tests were performed on a NiTi wire $(800 \mu \mathrm{m}$ diameter) which is the base of the considered endodontic files. The length of this wire was $16 \mathrm{~mm}$.

Then, we chose to test a smooth conical geometry. The experimental tests were carried out on a NiTi Revo Spreader ${ }^{\circledR}$ (300 $\mu \mathrm{m}$ tip diameter/.04 taper) (MicroMega).
Finally, the experimental tests were performed on two NiTi instruments with similar geometrical characteristics (diameter and taper): Hero $^{\circledR}(250 \mu \mathrm{m}$ tip diameter/.06 taper $)$ and OneShape ${ }^{\circledR}$.

2.1.2 Experimental Conditions. A tensile machine (Zwick ${ }^{\circledR}$, Ulm, Germany) with a bending setup was used. The bending effort versus the displacement was recorded. The applied bending effort was measured with a load sensor of $50 \mathrm{~N}$. The displacement was measured directly by the crosshead of the tensile machine with a resolution of $1 \mu \mathrm{m}$. The software used to acquire data was TestXpert ${ }^{\circledR}$ software (Zwick, Ulm, Germany).

The bending setup can be described as follows: A chuck is tightened in the inferior jaw of the tensile machine. In this chuck, the considered structure is inserted by its handle. Close to the free end of the structure, a rigid metallic blade applies a displacement to introduce bending. This blade is connected to the load cell, which is itself connected to the crosshead (Fig. 1).

2.1.3 Bending Tests on the Considered Structures. The boundary conditions varied according to the shape and the size of the different structures (NiTi wire, Revo Spreader ${ }^{\circledR}$, and the two instruments). Each limit condition was well adapted to each considered structure. Figure 2 presents the boundary conditions for each sample.

The displacement amplitude was $5 \mathrm{~mm}$ for the wire and the spreader. It was $2.5 \mathrm{~mm}$ for the endodontic instruments. The conditions of the experimental tests were quasi-static conditions.

\subsection{Numerical Simulations}

2.2.1 Meshing and Boundary Conditions. The NiTi wire, the Revo ${ }^{\circledR}$ Spreader, and the NiTi instruments (Hero ${ }^{\circledR}$ (250 $\mu \mathrm{m}$ tip diameter/.06 taper) and OneShape ${ }^{\circledR}$ ) were modeled according to the geometric information provided by the MicroMega manufacturer (Besançon, France) using its CAD files. They were meshed using the Cast $3 \mathrm{M}^{\circledR}$ finite element software (Commissariat Energie Atomique, Saclay, France) (Ref 41). All the geometrical characteristics of each instrument were taken into account (variable section, variable pitch, length, etc.). The elements used were solid tetrahedral elements with ten nodes (TE10). The number of nodes and elements for each geometric model is indicated in Fig. 3.

The same boundary conditions and bending loadings as in the experiments (Fig. 2) were numerically applied to these meshings of the different structures in Cast $3 \mathrm{M}^{\circledR}$. The conditions of the simulations were quasi-static conditions.

2.2.2 NiTi Behavior Model. All the simulations were carried out with an ad hoc model for superelasticity of SMA (Ref 40, 42), which had been implemented in Cast $3 \mathrm{M}^{\circledR}$. This model was developed especially for SMA materials and has several advantages: It can take into account the martensitic transformation, the tension/compression dissymmetry, and the effects of multiaxial and complex (i.e., out of phase) loadings.

In this model, concerning the kinematic assumptions, the small perturbation assumption is used. Thus, the total strain is decomposed in this way:

$\varepsilon=\varepsilon^{\mathrm{e}}+\varepsilon^{\mathrm{tr}}$

where $\varepsilon^{\mathrm{e}}$ and $\varepsilon^{\mathrm{tr}}$ are, respectively, the elastic and transformation strain tensors. 


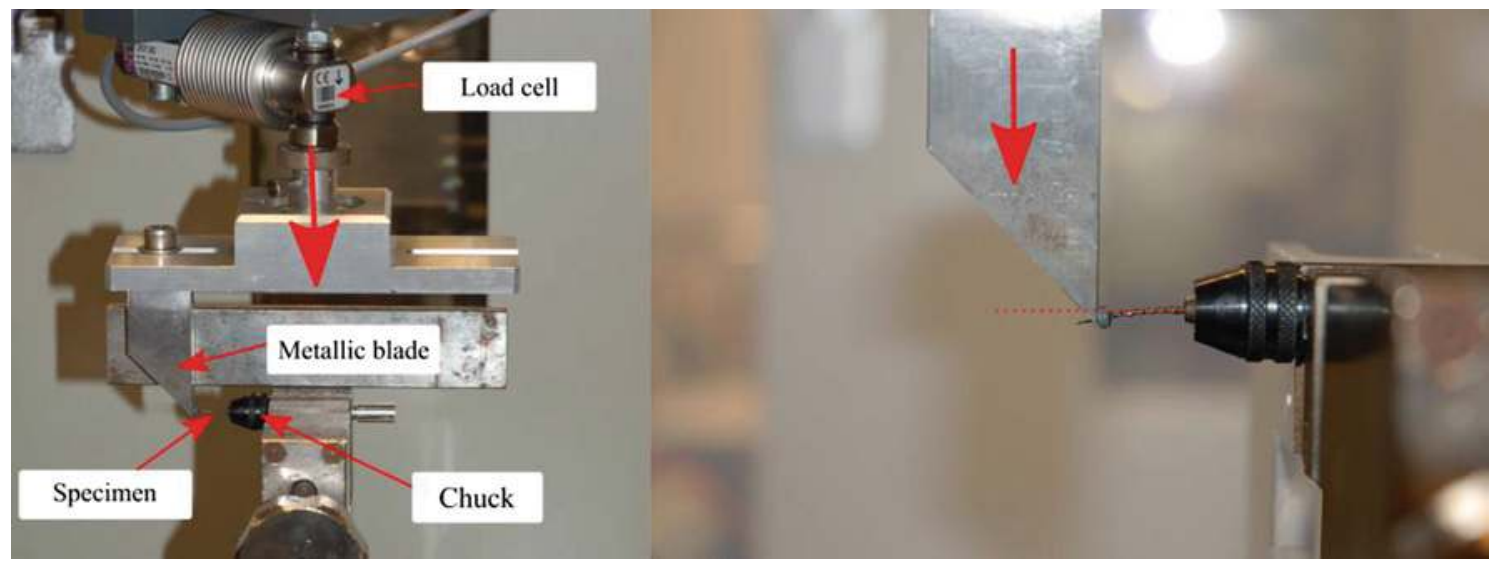

Fig. 1 Experimental setup used

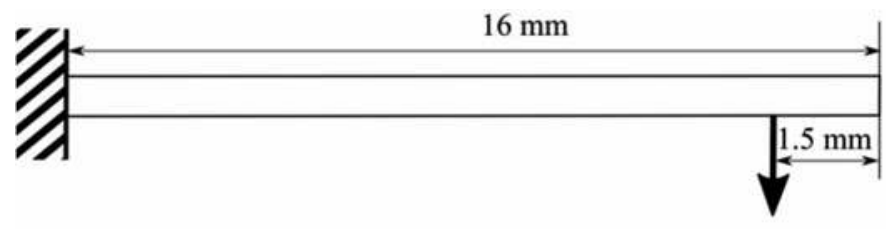

(a)

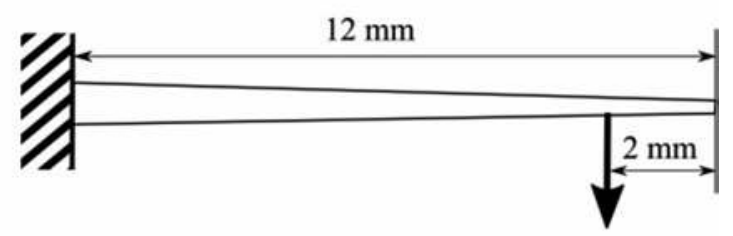

(b)

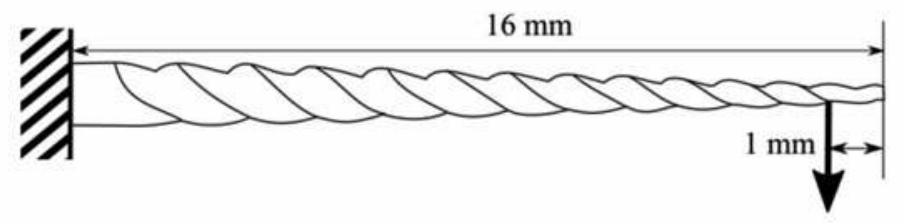

(c)

Fig. 2 (a) Boundary conditions of the experimental test on wire, (b) boundary conditions of the experimental test on Revo ${ }^{\circledR}$ Spreader, and (c) boundary conditions of the experimental test on endodontic instrument

The martensite volume fraction, $z$, is related to the SMA's equivalent transformation strain, $\varepsilon_{\mathrm{eq}}^{\mathrm{tr}}$ defined by (Ref 43,44$)$, as follows:

$z=\frac{\varepsilon_{\mathrm{eq}}^{\mathrm{tr}}}{\gamma}$

where $\gamma$ represents the maximum transformation strain of SMA.

In the model used, concerning the static assumptions, the forward phase transformation and the reverse phase transformation are, respectively, driven by transformation surfaces denoted as $f_{1}$ and $f_{2}$.

The forward phase transformation surface is defined by:

$f_{1}=\bar{\sigma}-\frac{R(z)+\sigma_{0}^{t}}{g\left(y_{\sigma}\right)} \leq 0$

where $\bar{\sigma}=\sqrt{\frac{3}{2} S: S}$ is the von Mises equivalent stress with:

- $\mathrm{S}$ is the deviatoric stress tensor,

- $g(y)=\cos \left(\frac{\arccos (1-a(1-y))}{3}\right)$ is a function which induces changes in the shape of the transformation surface and enables the description of the SMA asymmetry between ten- sion and compression with "a" as a material parameter which can vary from 0 to 1 ,

- $y_{\sigma}=\frac{27}{2} \frac{\operatorname{det}(S)}{\bar{\sigma}^{3}}$ is the third stress tensor invariant,

- $R(z)$ is a function, which describes the size of the transformation surface,

- And $\sigma_{O}^{t}$ is the tensile yield stress of forward phase transformation.

The equivalent stress used in this model is linked to von Mises equivalent stress, $\bar{\sigma}$, and to the $\mathrm{g}$ function:

$\sigma_{\mathrm{eq}}=\bar{\sigma} g\left(y_{\sigma}\right)$.

The shape and the size of the reverse transformation surface are defined in the same way:

$f_{2}=\overline{\sigma-X}-\frac{R(z)+\sigma_{0}^{t}}{g\left(y_{\sigma-X}\right)} \leq 0$,

with:

$y_{\sigma-X}=\frac{27}{2} \frac{\operatorname{det}(S-X)}{\sigma-X^{3}}$, 


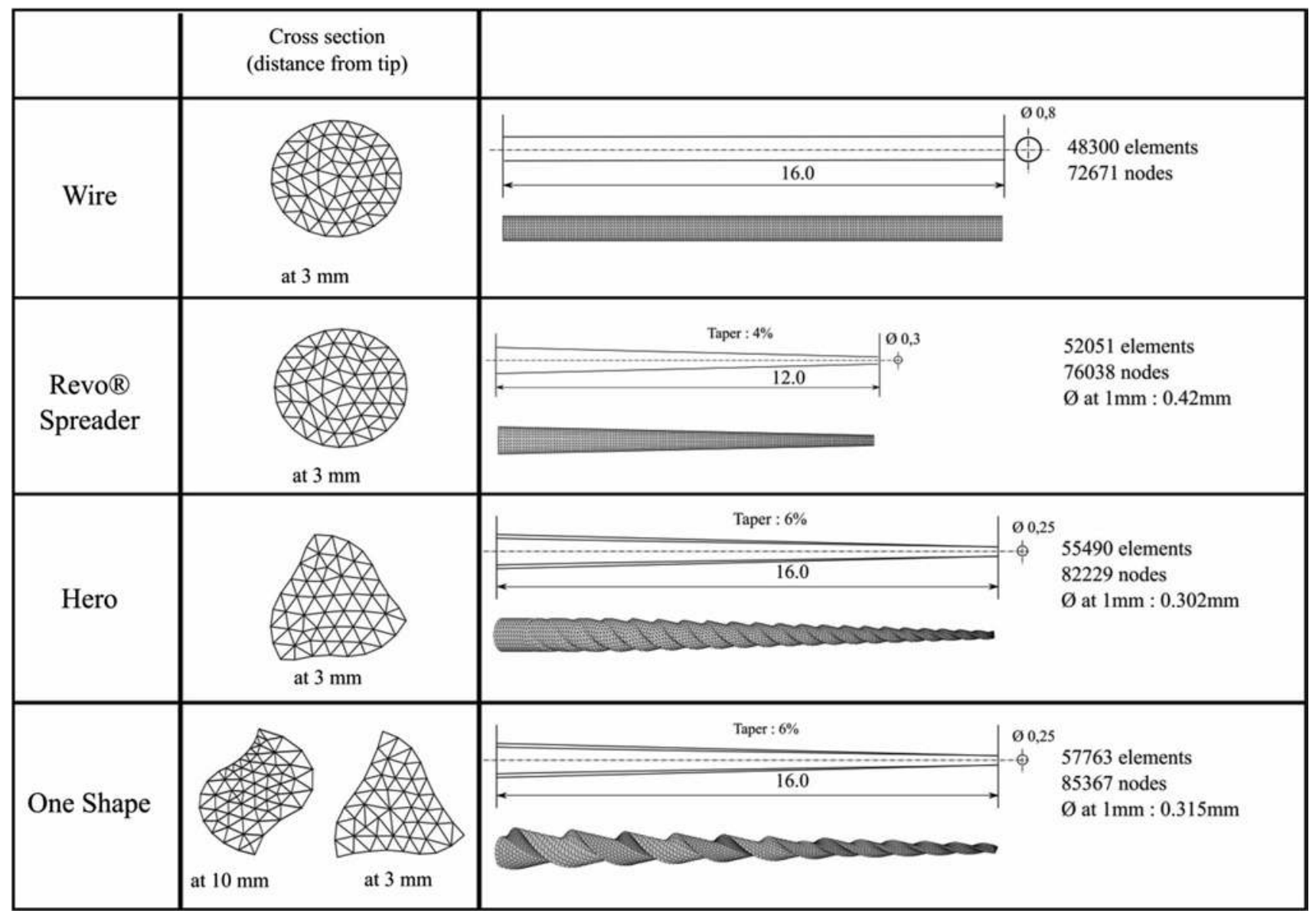

Fig. 3 Finite element meshing of the considered structures

where $X$ is the pseudo-hardening kinematic tensor which is collinear to $\varepsilon^{\text {tr }}$. It defines the position of the center of $f_{2}$ and is determined by the following equation:

$X=\left(\left(R(z)+\sigma_{0}^{t}\right)\left(\frac{1}{g\left(y_{\varepsilon}\right)}+\frac{1}{g\left(-y_{\varepsilon}\right)}\right)-\delta(z)\right) \frac{\varepsilon^{\mathrm{tr}}}{\sqrt{\frac{3}{2} \varepsilon^{\mathrm{tr}}: \varepsilon^{\mathrm{tr}}}}$,

where $\delta(z)$ is the size of the intersection between the two transformation surfaces $f_{1}$ and $f_{2}$ in the $\varepsilon^{\text {tr }}$ direction.

This model uses five parameters. The Poisson's ratio and the asymmetry parameter " $a$ " were determined from the literature (Ref 1). Other parameters were determined from a loading-unloading tensile test (Zwick machine, Ulm, Germany) up to $7.5 \%$ axial strain. The test was performed on the NiTi wire which had been used during the experimental bending tests. The mechanical parameters are presented in Table 1.

Figure 4 shows the experimental stress-strain curve and the numerical curve for a tensile test with identified material parameters of Table 1 .

It illustrates the efficacy of the superelastic model to correctly reproduce the hysteretic mechanical behavior of NiTi SMA, with no residual strain. The identified material parameters have been used for all the considered structures.
Table 1 List of material parameters of the model and their identified values

\begin{tabular}{ll}
\hline Parameters & \multicolumn{1}{c}{ Values } \\
\hline Young's modulus, $E$ & $47,000 \mathrm{MPa}$ \\
Yield stress, $\sigma_{0}^{t}$ & $505 \mathrm{MPa}$ \\
Poisson's ratio, $v$ & 0.3 \\
Asymmetry coefficient, $a$ & 0.76 \\
Maximum transformation strain, $\gamma$ & $6 \%$ \\
\hline
\end{tabular}

\section{Results}

\subsection{Experimental Results}

The reproducibility of experimental bending results was checked. An average curve is shown for each of the structures.

The first part of the results concerns the results of the NiTi wire and the Revo ${ }^{\circledR}$ Spreader (Fig. 5a and b).

The second part of the experimental results shows the comparison of the flexibility of the instruments (Fig. 5c).

The figures show the global behavior of each structure under bending: First, this behavior is elastic. After that, the behavior becomes nonlinear beyond a certain limit. This means that a certain amount of martensitic transformation develops in the 


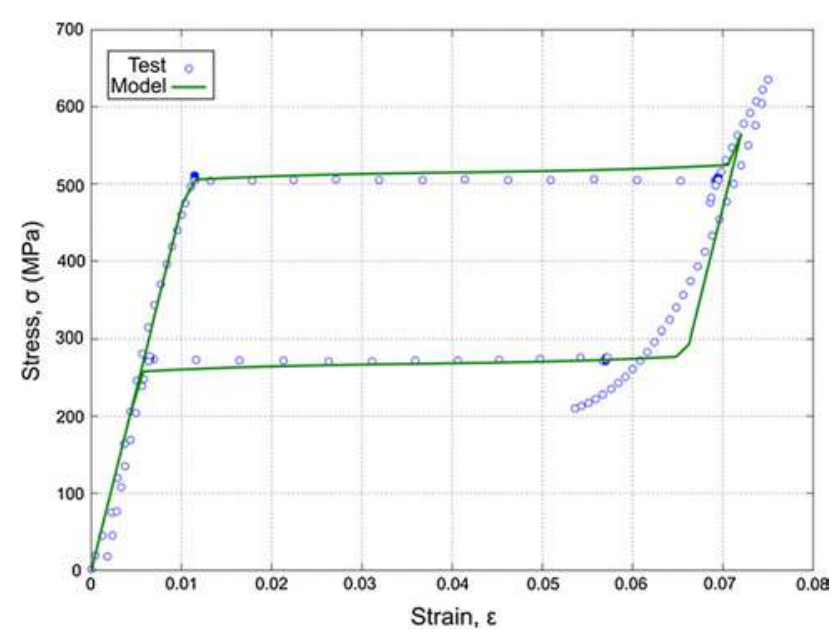

Fig. 4 Comparison of an experimental tensile test on a NiTi wire with a numerical stress-strain curve obtained with the superelastic numerical model

structure during the applied loading. Each of the structures has a hysteretic behavior. There is no residual strain after unloading. These results confirm the benefit of the superelasticity of NiTi. A classic alloy would have developed plasticity.

Figure 5(c) illustrates how the new-generation OneShape ${ }^{\circledR}$ instrument is much more flexible than the older Hero ${ }^{\circledR}$ instrument.

\subsection{A Comparison of Numerical and Experimental Results}

Numerical results were obtained for the different considered structures.

As experimental and numerical results were obtained with the same boundary conditions, a comparison between them is possible.

Figure 6 presents the experimental and numerical curves obtained for the wire (Fig. 6a), the Revo ${ }^{\circledR}$ Spreader (Fig. 6b) and the two NiTi instruments (Fig. 6c and d).

It can be noted that, for the wire and the Revo ${ }^{\circledR}$ Spreader, the experimental and numerical curves match very well (Fig. 6a and $b$ ).

Figure 6(c) and (d) shows that, for Hero ${ }^{\circledR}$ and One Shape ${ }^{\circledR}$ instruments, the experimental and numerical curves are in good agreement.

Numerical simulations can give additional information such as the equivalent stress distribution and the martensite volume fraction.

Figure 7(a) presents the equivalent stress distribution (SAMF) through the deformed geometries of the two instruments at the maximal bending. Figure 7(b) shows the martensite volume fraction $(Z)$ through the deformed geometries of the two instruments at the maximal bending.

These simulations highlight that during bending the maximal stress level is situated in the curved part of each structure, at a few millimeters from the apical end of the instruments. OneShape ${ }^{\circledR}$ shows a smaller area of maximal stress.

The simulations also show that the phase transformation is localized where the stress is maximal. The level of martensite volume fraction is higher for Hero ${ }^{\circledR}$ than for OneShape ${ }^{\circledR}$.

These results (Fig. 7) are due to the different geometrical parameters of the considered instruments.

\section{Discussion}

Several experimental setups have been described to study the bending behavior of endodontic NiTi instruments: not only the ISO 3630-1 test which is the most used (Ref 45), but also other setups such as cantilever bending tests (Ref 11, 46-48). The present study has proposed a new experimental setup, which enables bending to be applied on the structure of the instruments with good control over the boundary conditions. The proposed setup is simple and can be adapted in a tensile testing machine.

The results of the experimental tests show that the monoinstrument OneShape ${ }^{\circledR}$, whose mechanical behavior under bending is not extensively documented in the literature (Ref 11 ), is more flexible than a traditional instrument such as Hero ${ }^{\circledR}$. It shows that different instruments made from the same NiTi wire but with small geometrical differences do not have the same rigidity. Indeed, the variation in the cross section of OneShape ${ }^{\circledR}$ from the triple helix to the S-section, the asymmetric characteristic of OneShape ${ }^{\circledR}$ and the pitch variation contribute to making it more flexible than the older Hero ${ }^{\circledR}$ instrument. This is especially important in the context of a single instrument.

Once the experimental tests were conducted, they were used for comparison with the results of the numerical simulations performed with exactly the same boundary conditions.

The good match between experimental and numerical results can be explained by the use of a well-adapted NiTi behavior model (Ref 40, 42). This model is able to take into account the martensitic transformation and the superelastic behavior of NiTi. It reproduces the tension-compression dissymmetry which is very important with bending loadings, such as in this study. Among all the numerical studies carried out on NiTi endodontic instruments, only a few, such as (Ref 32-34, 39), used a well-suited model for NiTi SMA.

The novelty of this method lies in its comparison of experimental and numerical results. Several numerical studies on endodontic instruments were conducted but only very few of them quantitatively compared numerical with experimental results. Lee et al. (Ref 37 ) tried to assess whether there is a correlation between experimental cyclic fatigue resistance and numerical stress analysis for nickel-titanium rotary files. However, this comparison was not quantitative, and it was just a qualitative correlation. More recently, Santos et al. and Bonessio et al. quantitatively compared their numerical and experimental results to validate their simulations (Ref 16, 39). They proved the relevance of such an approach. However, they both used Auricchio's behavior model (Ref 49). We propose the same approach with Saint-Sulpice's SMA behavior model. In comparison with Auricchio's model, Saint-Sulpice's has the advantage of taking into account the effects of non-proportional and cyclic loadings, which can be important for future simulations of endodontic instrument behavior during root canal preparation. Moreover, this model has already been validated at the sample level (Ref 40), but not yet on structure. One of the aims of the present study has been to validate this model on different structures.

As this comparison between our simulations and experimental results is promising, even though the same material parameters were used for all the simulations, the simulations can be considered as validated. Consequently, the simulations performed can give additional local information. They can 


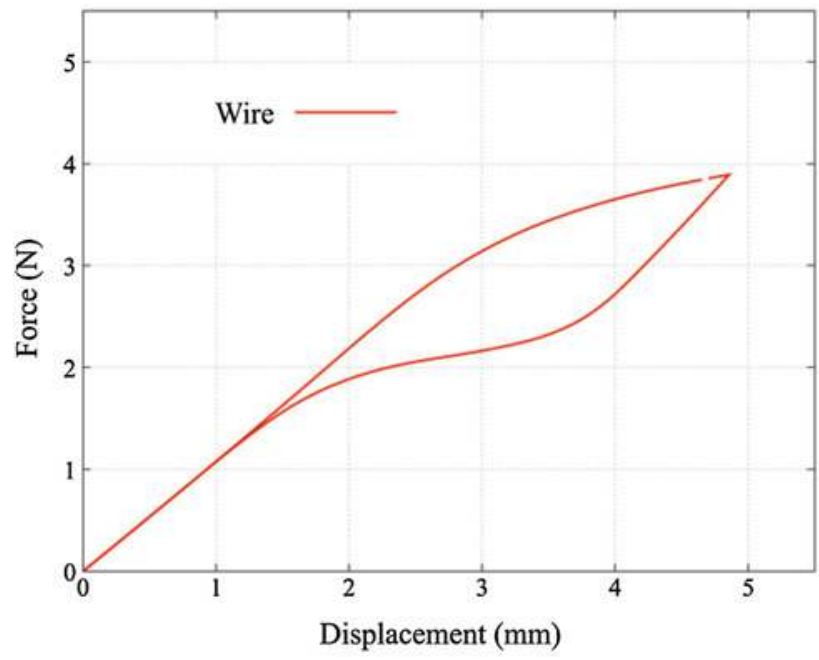

(a)

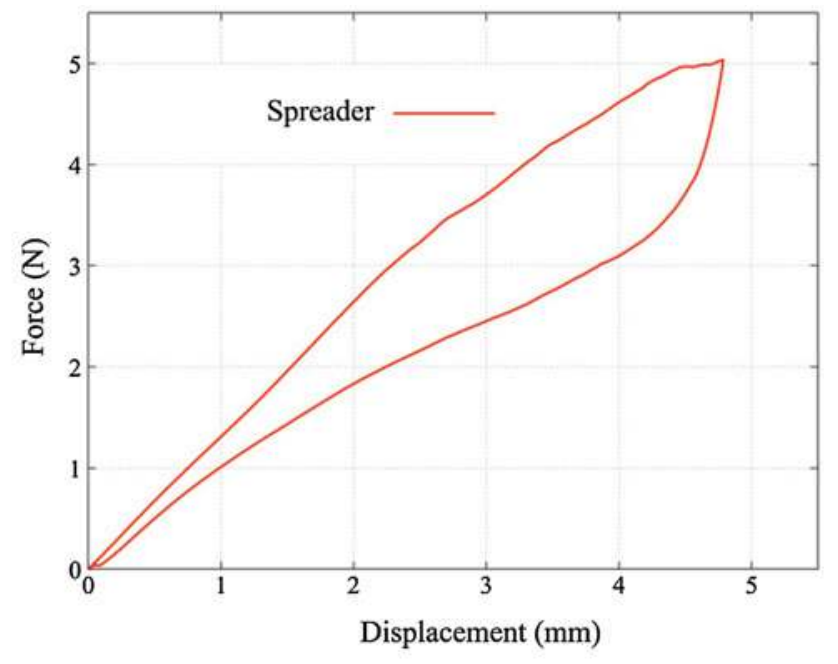

(b)

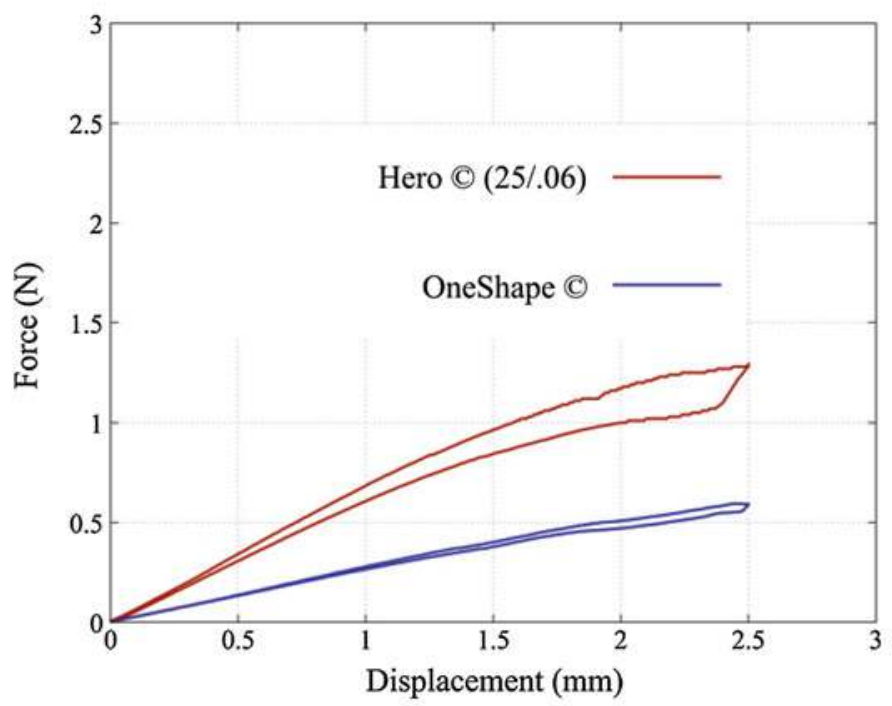

(c)

Fig. 5 Results of experimental tests of the considered structures. (a) Test with bending applied at $1.5 \mathrm{~mm}$ from the tip of the wire, (b) test with bending applied at $2 \mathrm{~mm}$ from the tip of the Revo ${ }^{\circledR}$ Spreader, and (c) test with bending applied at $1 \mathrm{~mm}$ from the tip of the two instruments

indicate the level of equivalent stress distribution (SAMF) and the martensite volume fraction at each point of the structure and during the whole loading path. Experimental tests cannot provide all these details. These results were analyzed at the maximal bending loading for the two endodontic instruments. OneShape ${ }^{\circledR}$ maximal stress and martensite volume fraction zones are smaller than those of Hero ${ }^{\circledR}$. These simulations confirm that OneShape ${ }^{\circledR}$ is more flexible than Hero ${ }^{\circledR}$, even with the same material parameters. This is purely due to geometrical characteristics.

This validation of simulations can allow us to use simulations to dimension new structures, and particularly new endodontic instruments.

Some points can be improved in order to reduce the small differences observed between experimental and numerical results. First, the accuracy of numerical meshing can be improved. Moreover, one may question whether the CAD files perfectly correspond to the real geometry of the instrument after machining. A solution to solve this issue could be the analysis of the real geometry of the instrument by microtomography. This method could indicate whether a difference exists between CAD files and machined instruments. In this case, new meshings could be created and new simulations could be carried out, in order to determine whether it reduces the difference between simulations and experimental results.

Another perspective relies on the improvement in material parameters of NiTi. In this study, the material parameters were deduced from a loading-unloading tensile test performed on a wire used by Micromega to manufacture endodontic instruments. They were numerically applied to all the structures. However, small variations in material parameters may exist between the structures, because the NiTi can come from different batches. For example, Young's modulus and the transformation yield stress can vary and affect the global stiffness of the structure. The identification of the material parameters on the shaft of the different structures could improve precision. This improvement in numerical simulations may help manufacturers to propose increasingly reliable files, 


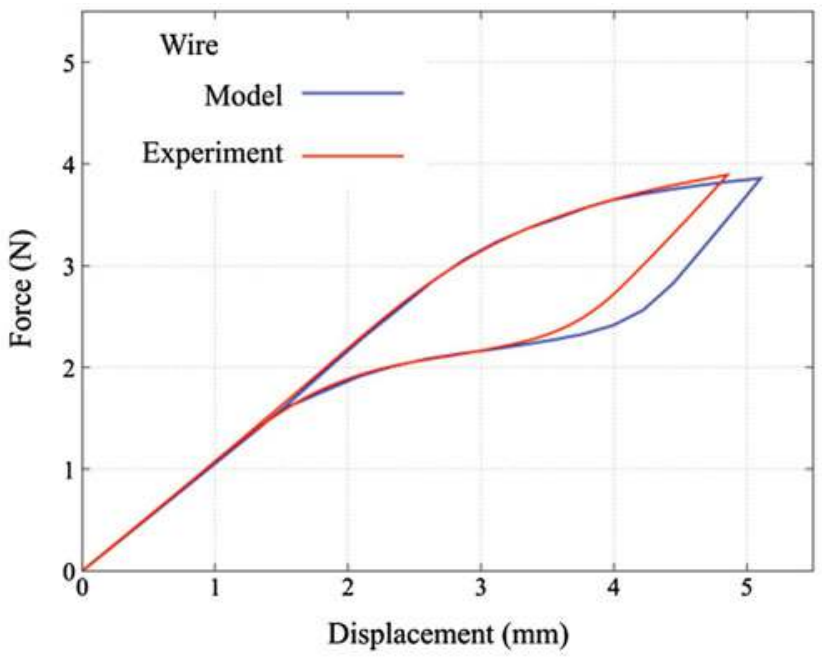

(a)

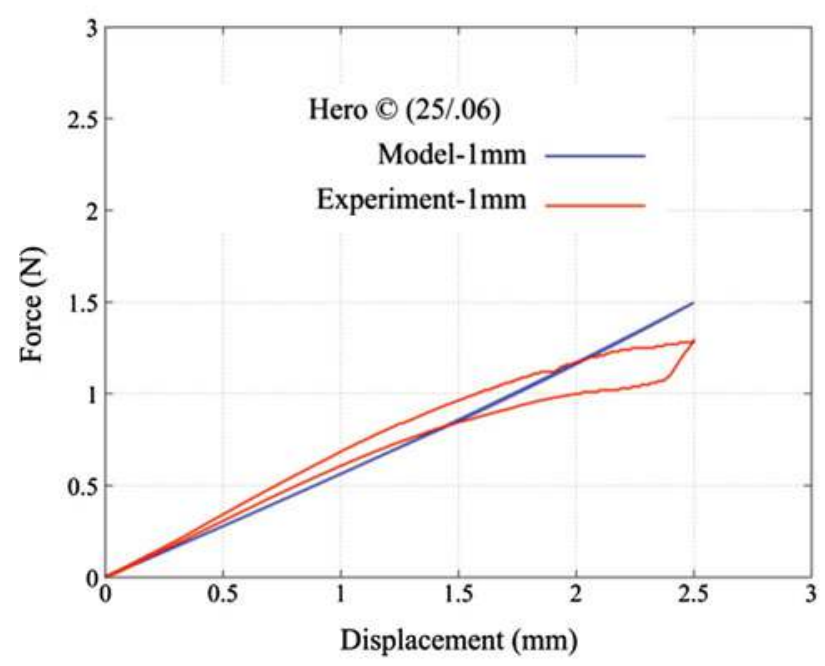

(c)

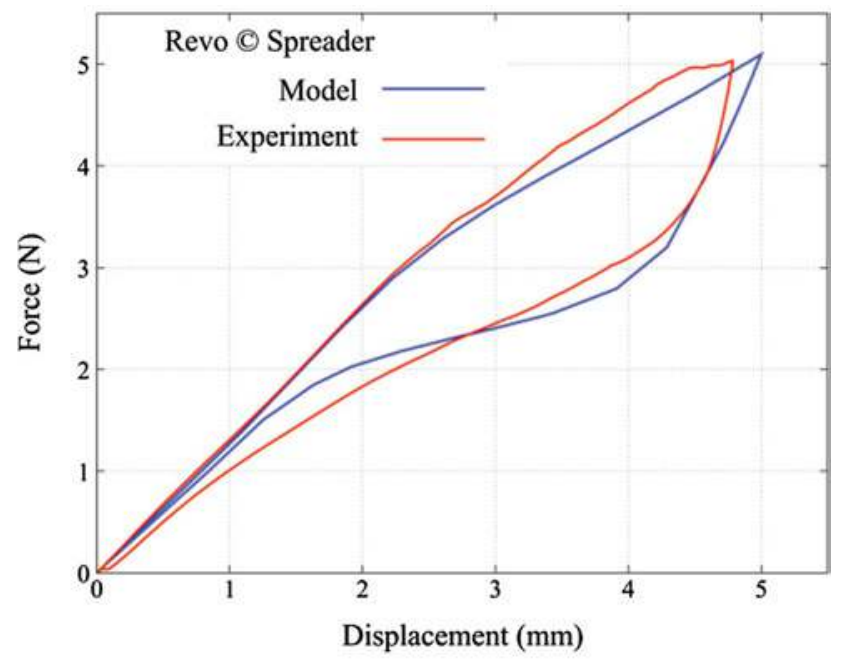

(b)

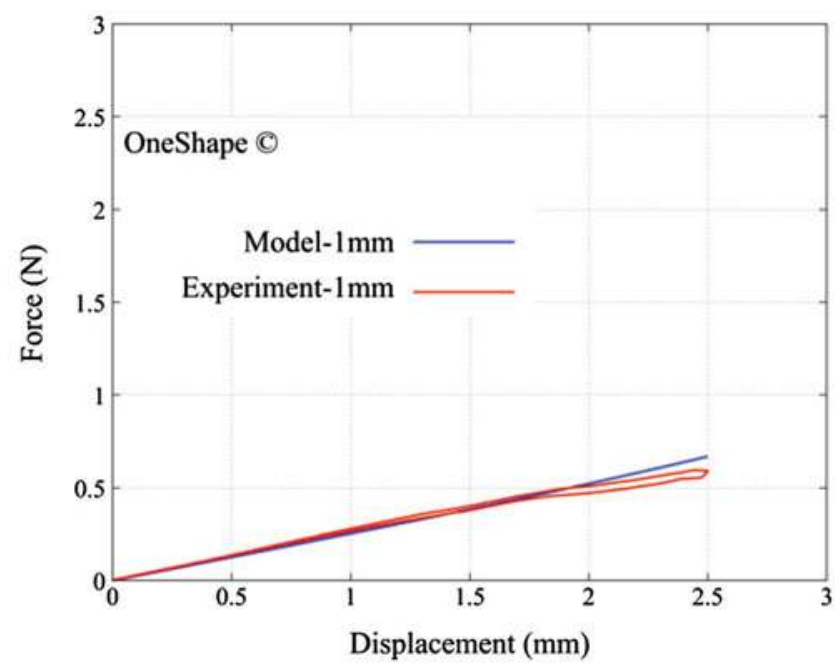

(d)

Fig. 6 Comparison between experimental tests and numerical simulations. (a) For the NiTi wire, (b) for the Revo ${ }^{\circledR}$ Spreader, (c) for Hero ${ }^{\circledR}$, and (d) for One Shape ${ }^{\circledR}$

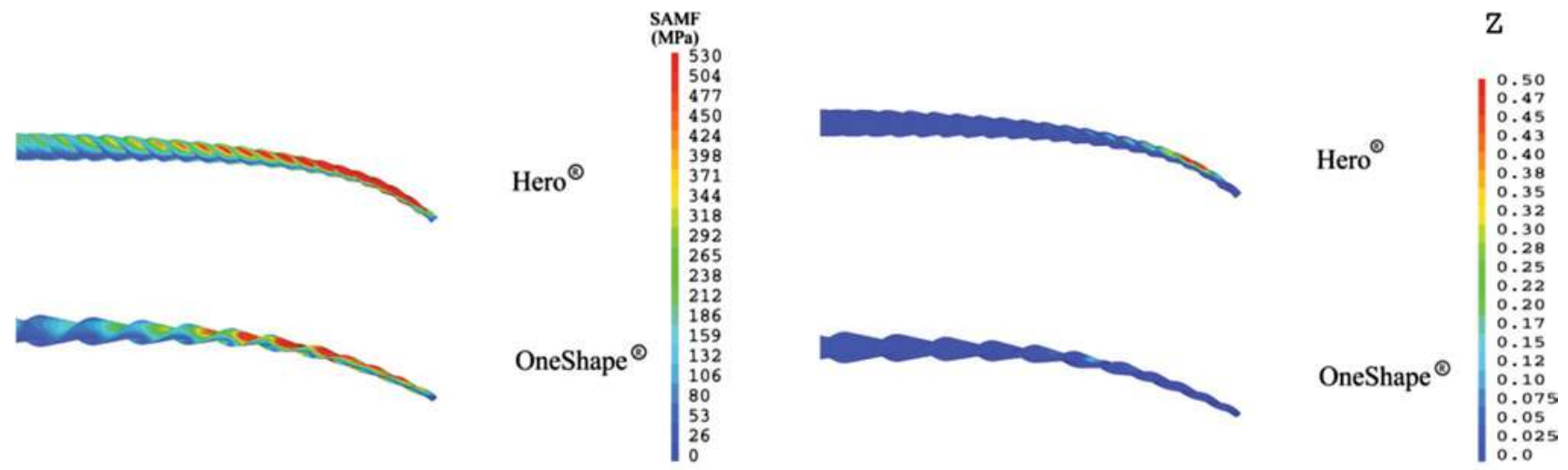

(a)

(b)

Fig. 7 Equivalent stress (SAMF) and martensite volume fraction $(Z)$ through the deformed geometries of the two instruments at the maximal bending 
especially nowadays as users demand great mechanical performance from their single-use instruments.

\section{Conclusion}

Experimental tests were carried out on structures of growing complexity: wire, spreader, and endodontic instruments. They showed that the new-generation OneShape ${ }^{\circledR}$ instrument is much more flexible under bending than the older Hero ${ }^{\circledR}$ instrument. All the experimental results were compared with numerical results, with the same structures, loadings, and boundary conditions. The orders of magnitude were similar. This numerical model was validated under bending. This model can provide global and local (equivalent stress and martensite volume fraction) information, which can enable the dimension of new NiTi structures and especially new NiTi endodontic instruments.

\section{References}

1. K. Otsuka and C.-M. Wayman, Shape Memory Materials, Cambridge University Press, Cambridge, 1999

2. D. Celik, T. Tasdemir, and K. Er, Comparative Study of Six Rotary Nickel-Titanium Systems and Hand Instrumentation for Root Canal Preparation in Severely Curved Root Canals of Extracted Teeth, $J$. Endod., 2013, 39(2), p 278-282

3. M. Hülsmann, O.A. Peters, and P.M.H. Dummer, Mechanical Preparation of Root Canals, Shaping Goals, Techniques and Means, Endod. Top., 2005, 10, p 30-76

4. B. Sattapan, G.J. Nervo, J.E. Palamara, and H.H. Messer, Defects in Rotary Nickel-Titanium Files After Clinical Use, J. Endod., 2000, 26, p 61-65

5. I.D. Capar and H. Arslan, A Review of Instrumentation Kinematics of Engine-Driven Nickel-Titanium Instruments, Int. Endod. J., 2016, 49(2), p 119-135. https://doi.org/10.1111/iej.12432

6. V. Franco, C. Fabiani, S. Tashieri, A. Malentacca, M. Bortolin, and M. Del Fabro, Investigation on the Shaping Ability of Nickel-Titanium Files When Used with a Reciprocation Motion, J. Endod., 2011, 37, p 1398-1401

7. G. Yared, Canal Preparation Using Only One NiTi Rotary Instrument: Preliminary Observations, Int. Endod. J., 2008, 41, p 339-344

8. R. Castello-Escriva, T. Alegre-Domingo, V. Faus-Matoses, S. RomanRichon, and V.J. Faus-Llacer, In vitro Comparison of Cyclic Fatigue Resistance of ProTaper WaveOne, and Twisted Files, J. Endod., 2012, 38, p 1521-1524

9. G. Gavini, C.L. Caldeira, E. Akisue, G.T. Candeiro, and D.A. Kawakami, Resistance to Flexural Fatigue of Reciproc R25 Files Under Continuous Rotation and Reciprocating Movement, J. Endod., 2012, 38, p 684-687

10. S. Burklein, S. Benten, and E. Schafer, Shaping Ability of Different Single-File Systems in Severely Curved Root Canals of Extracted Teeth, Int. Endod. J., 2013, 46, p 590-597

11. A.M. Elnaghy and S.E. Elsaka, Torsion and Bending Properties of OneShape and WaveOne Instruments, J. Endod., 2015, 41(4), p 544547. https://doi.org/10.1016/j.joen.2014.11.010 (Epub 2014 Dec 18)

12. S.E. Saber, M.M. Nagy, and E. Schafer, Comparative Evaluation of the Shaping Ability of WaveOne, c, Int. Endod. J., 2014, 48, p 109-114

13. S.E. Elsaka and A.M. Elnaghy, Cyclic Fatigue Resistance of OneShape and WaveOne Instruments Using Different Angles of Curvature, Dent. Mater. J., 2015, 34(3), p 358-363. https://doi.org/10.4012/dmj.2014252 (Epub 2015 Apr 23)

14. E. Karataş, H. Arslan, M. Büker, F. Seçkin, and I.D. Çapar, Effect of Movement Kinematics on the Cyclic Fatigue Resistance of NickelTitanium Instruments, Int. Endod. J., 2016, 49(4), p 361-364. https://d oi.org/10.1111/iej.12453 (Epub 2015 Apr 16)
15. Z. Wang, W. Zhang, and X. Zhang, Cyclic Fatigue Resistance and Force Generated by OneShape Instruments during Curved Canal Preparation, PLoS ONE, 2016, 11(8), p e0160815. https://doi.org/10. 1371/journal.pone. 0160815

16. N. Bonessio, E.S. Pereira, G. Lomiento, A. Arias, M.G. Bahia, V.T. Buono, and O.A. Peters, Validated Finite Element Analyses of WaveOne Endodontic Instruments: A Comparison Between M-Wire and NiTi Alloys, Int. Endod. J., 2015, 48(5), p 441-450. https://doi. org/10.1111/iej.12333 (Epub 2014 Jul 12)

17. G.P. Kumar and L. Mathew, Self-expanding aortic valve stent-material optimization, Comput. Biol. Med., 2012, 42(11), p 1060-1063. https://d oi.org/10.1016/j.compbiomed.2012.08.007 (Epub 2012 Sep 14)

18. F. Nematzadeh and S.K. Sadrnezhaad, Effects of Crimping on Mechanical Performance of Nitinol Stent Designed for Femoral Artery: Finite Element Analysis, J. Mater. Eng. Perform., 2013, 22, p 3228. h ttps://doi.org/10.1007/s11665-013-0635-7

19. M. Kromka-Szydek, M. Jedrusik-Pawłowska, G. Milewski, Z. Lekston, T. Cieślik, and J. Drugacz, Numerical Analysis of Displacements of Mandible Bone Parts Using Various Elements for Fixation of Subcondylar Fractures, Acta Bioeng. Biomech., 2010, 12(1), p 11-18

20. E. Berutti, G. Chiandussi, I. Gaviglio, and A. Iba, Comparative Analysis of Torsional and Bending Stresses in Two Mathematical Models of Nickel Titanium Rotary Instruments: Protaper Versus Profile, J. Endod., 2003, 29(1), p 15-19

21. Y.L. Turpin, F. Chagneau, O. Bartier, G. Cathelineau, and J.M. Vulcain, Impact of Torsional and Bending Inertia on Root Canal Instruments, $J$. Endod., 2001, 27(5), p 333-336

22. Y.L. Turpin, F. Chagneau, and J.M. Vulcain, Impact of Two Theoretical Cross-Sections on Torsional and Bending Stresses of Nickel Titanium Root Canal Instrument Models, J. Endod., 2000, 26(7), p 414-417

23. X. Xu, M. Eng, Y. Zheng, and D. Eng, Comparative Study of Torsional and Bending Properties for Six Models of Nickel-Titanium Root Canal Instruments with Different Cross-Sections, J. Endod., 2006, 32, p 372375

24. R. Arbab Chirani, V. Chevalier, S. Arbab Chirani, and S. Calloch, Comparative Analysis of Torsional and Bending Behavior Through Finite-Element Models of Five NiTi Endodontic Instruments, Oral Surg. Oral Med. Oral Pathol. Oral Radiol. Endod., 2011, 111(1), p $115-121$

25. S.H. Baek, C.J. Lee, A. Versluis, B.M. Kim, W. Lee, and H.C. Kim, Comparison of Torsional Stiffness of Nickel-Titanium Rotary Files with Different Geometric Characteristics, J. Endod., 2011, 37, p 12831286

26. R. He and J. Ni, Design Improvement and Failure Reduction of Endodontic Files Through Finite Element Analysis: Application to VTaper File Designs, J. Endod., 2010, 36(9), p 1552-1557

27. T.O. Kim, G.S.P. Cheung, J.M. Lee, B.M. Kim, B. Hur, and H.C. Kim, Stress Distribution of Three NiTi Rotary Files Under Bending and Torsional Conditions Using a Mathematic Analysis, Int. Endod. J., 2009, 42, p 14-21

28. E.W. Zhang, G.S.P. Cheung, and Y.F. Zheng, Influence of Crosssectional Design and Dimension on Mechanical Behavior of NickelTitanium Instruments Under Torsion and Bending: A Numerical Analysis, J. Endod., 2010, 36(8), p 1394-1398

29. M.I. El-Anwar, S.A. Yousief, E.M. Kataia, and T.M. El-Wahab, Finite Element Study on Continuous Rotating Versus Reciprocating NickelTitanium Instruments, Braz. Dent. J., 2016, 27(4), p 436-441. https://d oi.org/10.1590/0103-6440201600480

30. D. Montalvao and F.S. Alcada, Numeric Comparison of the Static Mechanical Behavior Between Profile GT and Profile GT Series X Rotary Nickel-Titanium Files, J. Endod., 2011, 37(8), p 1158-1161

31. L.D.A. Santos, M.G. Bahia, E.B. de Las Casas, and V.T. Buono, Comparison of the Mechanical Behavior Between Controlled Memory and Superelastic Nickel-Titanium Files Via Finite Element Analysis, $J$. Endod., 2013, 39(11), p 1444-1447. https://doi.org/10.1016/j.joen.20 13.07.030 (Epub 2013 Sep 8)

32. L.D.A. Santos, P.D. Resende, M.G. Bahia, and V.T. Buono, Effects of R-Phase on Mechanical Responses of a Nickel-Titanium Endodontic Instrument: Structural Characterization and Finite Element Analysis, Sci. World J., 2016, https://doi.org/10.1155/2016/7617493

33. S. Necchi, S. Taschieri, L. Petrini, and F. Migliavacca, Mechanical Behavior of Nickel-Titanium Rotary Endodontic Instruments in Simulated Clinical Conditions: A Computational Study, Int. Endod. J., 2008, 41, p 939-949 
34. S. Necchi, L. Petrini, S. Taschieri, and F. Migliavacca, A Comparative Computational Analysis of the Mechanical Behavior of Two NickelTitanium Rotary Endodontic Instruments, J. Endod., 2010, 36(8), p $1380-1384$

35. H.C. Kim, H.J. Kim, C.J. Lee, B.M. Kim, J.K. Park, and A. Versluis, Mechanical Response of Nickel-Titanium Instruments with Different Cross-Sectional Designs During Shaping of Simulated Curved Canals, Int. Endod. J., 2009, 42, p 593-602

36. H.C. Kim, M.H. Lee, J. Yum, H.J. Kim, A. Versluis, C.J. Lee, and B.M. Kim, Potential Relationship Between Design of Nickel-Titanium Rotary Instruments and Vertical Root Fracture, J. Endod., 2010, 36(7), p 1195-1198

37. M.H. Lee, A. Versluis, B.M. Kim, C.J. Lee, B. Hur, and H.C. Kim, Correlation Between Experimental Cyclic Fatigue Resistance and Numerical Stress Analysis for Nickel-Titanium Rotary Files, J. Endod., 2011, 37(8), p 1152-1157

38. V. Legrand, S. Moyne, L. Pino, S. Arbab Chirani, S. Calloch, V. Chevalier, and R. Arbab Chirani, Mechanical Behavior of a NiTi Endodontic File During Insertion in an Anatomic Root Canal Using Numerical Simulations, J. Mater. Eng. Perform., 2015, 24, p 4941. h ttps://doi.org/10.1007/s11665-015-1799-0

39. L.D.A. Santos, J.B. López, E.B. de Las Casas, M.G. de Azevedo Bahia, and V.T. Buono, Mechanical Behavior of Three NickelTitanium Rotary Files: A Comparison of Numerical Simulation with Bending and Torsion Tests, Mater. Sci. Eng. C Mater. Biol. Appl., 2014, 37, p 258-263. https://doi.org/10.1016/j.msec.2014.01.025 (Epub 2014 Jan 15)

40. L. Saint-Sulpice, S. Arbab-Chirani, and S. Calloch, Thermomechanical Cyclic Behavior Modeling of Cu-AL-Be SMA Materials and Structures, Int. J. Solids Struct., 2012, 49(9), p 1088-1102

41. Cast3M. http://www-cast3m.cea.fr. Accessed 18 Jan 2018
42. L. Saint-Sulpice, S. Arbab Chirani, and S. Calloch, A 3D Super-Elastic Model for Shape Memory Alloys Taking into Account Progressive Strain Under Cyclic Loadings, Mech. Mater., 2009, 41, p 12-26

43. C. Bouvet, S. Calloch, and C. Lexcellent, A Phenomenological Model for Pseudoelasticity of Shape Memory Alloys Under Multiaxial Proportional and Nonproportional Loadings, Eur. J. Mech. A. Solids, 2004, 23, p 37-61

44. K. Taillard, S. Arbab Chirani, S. Calloch, and C. Lexcellent, Equivalent Transformation Strain and Its Relation with Martensite Volume Fraction for Isotropic and Anisotropic Shape Memory Alloys, Mech. Mater., 2008, 40(4-5), p 151-170

45. International Organization for Standardization, Dentistry Root-Canal Instruments-Part 1: General Requirements and Test Methods, ISO 3630-1 (2008)

46. H.P. Lopes, C.N. Elias, M.V. Vieira, J.F. Jr., M. Siqueira, W.S. Mangelli, V.T. Lopes, F.R. Vieira, J.C. Alves, and T.G.Soares Oliveira, Fatigue Life of Reciproc and Mtwo Instruments Subjected to Static and Dynamic Tests, J. Endod., 2013, 39(5), p 693-696. https://doi.org/10. 1016/j.joen.2012.11.048 (Epub 2013 Feb 8)

47. J. Piao, K. Miyara, A. Ebihara, N. Nomura, T. Hanawa, and H. Suda, Correlation Between Cyclic Fatigue and the Bending Properties of Nickel Titanium Endodontic Instruments, Dent. Mater. J., 2014, 33(4), p 539-544

48. H.M. Zhou, Y. Shen, W. Zheng, L. Li, Y.F. Zheng, and M. Haapasalo, Mechanical Properties of Controlled Memory and Superelastic NickelTitanium Wires Used in the Manufacture of Rotary Endodontic Instruments, J. Endod., 2012, 38(11), p 1535-1540. https://doi.org/10. 1016/j.joen.2012.07.006 (Epub 2012 Sep 10)

49. F. Auricchio and L. Petrini, A Three-Dimensional Model Describing Stress-Temperature Induced Solid Phase Transformations: Solution Algorithm and Boundary Value Problems, Int. J. Numer. Meth. Eng., 2004, 61, p 807-836 